\title{
Novo Avenida Brasil 2 - O olhar do estrangeiro no Brasil
}

\author{
Elisa Novaski Cordeiro \\ Universidade Tecnológica Federal do Paraná
}

\begin{abstract}
Resumo
Este trabalho analisa algumas atividades com enfoque intercultural propostas no livro Novo Avenida Brasil 2. O objetivo é verificar se elas se mostram relevantes para os alunos e se podem contribuir com a evolução de seu aprendizado na língua alvo, já que esses estudantes se encontram em situação de imersão.
\end{abstract}

Palavras chave: Português para falantes de outras línguas, abordagem cultural, livro didático.

\begin{abstract}
This paper analyses activities with an intercultural focus from the Novo Avenida Brasil 2 course book. It aims to verify whether such activities are indeed relevant to students and whether they contribute to the students' learning process in the target language within a linguistic immersion context.

Keywords: cultural approach, textbook, Portuguese for speakers of other languages
\end{abstract}

\section{O ENSINO DE PFOL NO BRASIL}

A escolha do Brasil por estrangeiros como destino de nova morada - definitiva ou transitória - por diferentes motivos representa uma cifra que vem crescendo cada vez mais (DUTRA, 2008; SELLAN, 2012). Segundo Dutra (2008), esse crescimento vem repercutindo na produção de pesquisas e tentativas de avanço no que se refere ao ensino de Português Para Falantes de Outras Línguas (doravante PFOL).

Nossa escolha pela nomenclatura - PFOL -, dentre outras possibilidades, como pontuado por Dutra (2008), deve-se à pesquisa realizada neste trabalho específico: contamos com um universo crescente de estrangeiros/falantes de outras línguas vivendo no Brasil, em uma situação de imersão. Essas pessoas precisam aprender o idioma para se comunicar e viver em nosso país. Nesse sentido, o ensino de português ganha uma nova visão: conforme pontuado por Almeida Filho (2005), ensinar português como língua materna, tal qual aprendemos na escola nas aulas de língua portuguesa, é completamente diferente de ensinar português para falantes de outras línguas.

Além disso, deve-se levar em conta que esse tipo específico de ensino traz outra particularidade: como os alunos estão em uma situação de imersão, seu contato com a 
língua estrangeira não se resume à sala de aula, mas abrange todo o seu dia ou, pelo menos, grande parte dele. Tendo em vista essa diferenciação, Cunha (2007, p. 13) salienta:

Com efeito, ensinar português como língua materna não é a mesma coisa do que ensinar português como segunda língua a membros de grupos autóctones ou a membros de comunidades transplantadas. Também não é o mesmo que ensinar português como língua estrangeira. (CUNHA, 2007, p. 13)

Almeida Filho (2005) distingue o ensino de língua em duas grandes e principais raízes: L1 (primeira língua) e LO (outra língua) ou LN (nova língua). A partir desta segunda, que é a que nos interessa neste trabalho, temos L2/LS ou LE. A partir das duas, há várias outras divisões, com as quais não nos deteremos, destacando somente a seguinte definição: o contexto de L2/LS se refere, resumidamente, à língua aprendida em situações de imersão e a LE se refere a: "experiência educacional na escola enquanto disciplina do currículo" (ALMEIDA FILHO, 2005, p. 7).

Temos, portanto, outro ponto importante: quando se trata de PFOL no Brasil, além de se ensinar português como língua estrangeira, ou seja, diferenciando-se do ensino de língua materna, estamos nos referindo a pessoas que estudam o português em situação de imersão. Em outras palavras, elas, ao mesmo tempo em que estudam a língua estrangeira, prescindem dela para viver no país. Assim sendo, não se trata de ensinar português como língua estrangeira somente, mas ensinar português a aprendizes em situação de imersão. Como o contato com a língua alvo, para esses aprendizes, é constante, as dúvidas, as motivações e o ritmo de aprendizagem se mostram muito diferentes do que para alunos que têm aulas de língua estrangeira em seu próprio país.

Pese-se a esses pormenores envolvendo o ensino de PFOL no Brasil o fato de que ainda enfrentamos muitos problemas em relação ao arcabouço teórico metodológico inerente a essa atividade. Sellan (2012, p. 27) chama a atenção para esse fato no seguinte trecho:

Por se tratar de uma atividade ainda incipiente, observamos indefinições a respeito de quais caminhos devemos adotar para tornar sua prática realmente efetiva, no sentido de propiciar ao aprendiz estrangeiro sucesso no novo aprendizado e ao professor certeza da tarefa bem realizada. Tais indefinições podem ser constadas em relação à pedagogia adotada, à teoria subjacente, aos temas abordados, ao material didático preparado, entre os quais a seleção do livro didático e à proposição de atividades extra-sala de aula que complementem conteúdos e oportunizem ao aluno experienciar o que lhe é apresentado nas aulas. (SELLAN, 2012, p. 27) 
A autora aborda um tema de fundamental relevância nesse ponto: os materiais didáticos e, mais especificamente, o livro didático adotado. Nenhum livro didático será capaz de atender a todas as necessidades do aprendiz e do professor, pois ele é um material de apoio. No entanto, há alguns pontos importantes que precisam ser levados em conta na escolha do material. Neste trabalho específico, nosso foco diz respeito à abordagem cultural constante no livro didático, no seguinte sentido: de que modo a abordagem cultural trazida pelo livro retrata o que os alunos vivenciam, em termos de cultura no dia a dia, em suas ocupações básicas, tais como, estudo, trabalho, compras e relações com outras pessoas. Além disso, podemos considerar que abordar temas culturais representa uma ferramenta auxiliadora na relação com este novo mundo que, para esse aprendiz, é o país estrangeiro?

\section{JUSTIFICATIVA E OBJETIVO}

Aprender uma língua estrangeira não se restringe ao conhecimento linguístico da língua. Falar uma língua abarca muitos outros fatores, entre eles, encontram-se as visões sócio-histórico-culturais. As questões relacionadas ao código linguístico podem ser solucionadas, mas aquelas que tocam na identidade e no aspecto cultural se revelam, muitas vezes, como entraves (SELLAN, 2012).

Partindo do pressuposto de que possibilitar a comunicação é a atividade dominante no ensino de língua estrangeira (GODOI, 2001) e somando a essa ideia a definição de comunicação como um processo cultural (LARAIA, 2006), concluímos que a comunicação e a cultura estão intimamente conectadas. Desse modo, a cultura precisa ser tratada como parte integrante da língua e não pode ser abordada em sala de modo fragmentado, vista como uma "quinta habilidade" a ser trabalhada (FRANÇA e SANTOS, 2008).

A grande maioria dos materiais didáticos reconhece a importância da cultura inserida em um contexto de ensino de línguas. Porém, ainda há muitas dú vidas em relação ao modo como fazê-lo. Cordeiro e Werner (2011) analisam alguns livros didáticos no que se refere à abordagem cultural e observam que, dentro desses manuais, há uma preocupação em abordar questões culturais, o problema é que essa abordagem, em geral, acontece de modo fragmentado. Ou seja, na maioria dos casos, ela se restringe a dicas inseridas a título de curiosidade ou, então, a uma sessão à parte da unidade temática, geralmente através de um texto que comenta sobre um costume, um hábito, uma festa. Não há uma preocupação em se abordar questões culturais de modo mais profundo, como um sistema de crenças e valores realmente. A cultura aparece, em geral, como uma peça de folclore, como uma 
curiosidade, como um dado histórico. Godoi (2005, p. 1) destaca: "se queremos formar a competência comunicativa do aluno, temos que lhe apresentar aquele mínimo de conhecimentos e representações que estão na mente da maioria dos falantes da língua".

Há certas expressões entendidas e reproduzidas pelos falantes de uma determinada região que não fazem o menor sentido para um estrangeiro, já que este só se valerá do sentido literal dessas expressões. Termos como: "vestir a camisa", "entrar pelo cano", "não entender bulhufas", "nossa senhora" fazem parte de nossos discursos e de nossa cultura, mas não fazem sentido se consideramos somente o significado literal (CORDEIRO e WERNER, 2011).

À parte das expressões linguísticas, existem ainda muitos fatores culturais que se integram à língua. Por exemplo, a fala coloquial hispânica, além de espontânea, subjetiva e afetiva, é desde o ponto de vista linguístico, eminentemente dêitica e egocêntrica, repleta de expressões como: "Te lo digo yo"; "Creo yo"; "Yo lo creo" (VIGARA, 1987 apud GODOI, 2001, p. 327). Assim como vale ressaltar o uso de expressões usadas para chamar a atenção: "Fíjate"; "Fígurese", ou as numerosas designações que realçam a expressão no sentido positivo: "un montón de"; "una barbaridad"; "un titipuchal" (Mex.) (GODOI, 2001, p. 328). Enfim, esses são alguns exemplos do que também pode ser levado em conta na abordagem cultural em sala.

Laraia (2006) também levanta uma importante questão com o seguinte exemplo: para uma mulher de cultura ocidental, criada sob os preceitos de qualquer religião cristã, pensar em matar seu próprio filho é impossível e seria, dentro de nossa cultura, um crime que, seguramente, chocaria toda a sociedade. Porém, para uma mulher Tapirapé, tribo Tupi do norte do Mato Grosso, essa era uma atividade, além de normal, completamente aceita, já que as mulheres, por crenças religiosas, teriam que matar todos os filhos após o terceiro, sem se sentirem culpadas por tal ato.

O aprendiz precisa ser levado, portanto, a compreender o que motiva as pessoas de determinada comunidade a agirem de um modo específico sem, com isso, classificar essas ações como melhores ou piores. Nesse sentido, podemos levantar a seguinte questão: até que ponto um livro didático pode auxiliar os aprendizes a refletir, a compreender e a se familiarizar com a cultura "estrangeira"? Para responder essa pergunta, buscaremos escutar o que alguns alunos que frequentam aulas de PFOL têm a nos dizer. Os alunos participantes da pesquisa obedecem aos seguintes critérios: são estrangeiros que vivem no Brasil e vivenciam, em seu dia a dia, a tarefa de compreender e viver em uma cultura 
diferente da sua. É muito diferente do caso de pessoas que estudam uma língua estrangeira em seu próprio país e não têm um contato tão direto com a língua alvo.

Tendo em vista essa temática, o objetivo deste trabalho é analisar se três atividades didáticas com enfoque em aspectos culturais propostas pelo livro Novo Avenida Brasil 2 foram relevantes e se se mostraram úteis para alunos pertencentes a um grupo de hispânicos aprendizes de PFOL.

\section{APRENDIZAGEM DE LÍNGUAS ESTRANGEIRAS E ABORDAGEM CULTURAL}

Sobre o aprendizado de línguas estrangeiras, Godoi (2005) afirma que a tarefa de aprender uma nova língua não pode ser vista como aprender novas informações sobre léxico, gramática e pronúncia. Mais do que isso, a autora destaca que aprender uma nova língua significa adquirir novos elementos simbólicos de uma comunidade diferente. Em outras palavras, as novas palavras não são simplesmente novos rótulos para conceitos já conhecidos, a nova gramática não se resume simplesmente a uma nova forma de ordenar e organizar as palavras, assim como a pronúncia não significa uma nova maneira de articular os sons.

Levando em conta as considerações da autora, percebe-se que é impossível estudar ou ensinar uma língua estrangeira carregando a visão de que a língua se organiza em grandes blocos: gramática, vocabulário, pronúncia e cultura e, dessa forma, estudar cada bloco separadamente. A língua é um todo e precisa ser entendida dessa maneira. Cordeiro e Werner (2011) analisam a evolução da abordagem cultural no ensino de língua estrangeira, destacando que houve um avanço ao longo dos anos: desde o entendimento da cultura como uma "ilustração" até a visão de cultura como parte integrante da língua.

Mas, mesmo havendo muitos avanços, ainda há algumas compreensões equivocadas sobre a abordagem cultural em sala. Muitas vezes, acredita-se que diversidade cultural se resume às diferenças de vocabulário presentes em diferentes regiões que falam o mesmo idioma (GODOI, 2001). Outro engano é restringir a abordagem cultural à exposição de tópicos relacionados à história, geografia, festas, folclore. Nesse sentido, Godoi (2005, p. 1) destaca: 
aqueles que se atribuem o direito de ensinar línguas e sobre línguas - preparam aulas, palestras e cursos sobre as festas nacionais, culinária, costumes, etc. Tudo isso obrigatoriamente com o sabor de exotismo folclórico. Nas entrelinhas dos ensinamentos desses profissionais se lê algo como: "olha como 'eles' são esquisitos, olha que porcarias 'eles' conseguem comer, olha se esse é o jeito de se divertir!". Tal exotismo pode tomar outros rumos, aparentemente contrários, mas que, como produto final, refletem a mesma postura: "experimenta esta paella, é divina, isso não é o nosso arroz com feijão!", "a festa do 4 de julho isso sim que é uma festa!", e assim por diante. (GODOI, 2005, p. 1).

Tal postura não só prejudica a aprendizagem, como favorece a criação de estereótipos negativos, pois o professor sempre assume uma posição de comparação, colocando as culturas (materna e estrangeira) sempre em contraste, de modo a chamar a atenção para uma ou outra como melhor ou pior. Esse problema é também levantado por Cordeiro e Werner (2011) que afirmam que a cultura é vista de maneira superficial, o que leva à criação de estereótipos, causando a identificação do falante nativo da língua alvo como estrangeiro, prejudicando, desse modo, a correta compreensão de que se trata, simplesmente, de diferentes formas de ver e de entender o mundo a sua volta.

Para que não haja essa visão deturpada de cultura, é essencial definir o que se entende por esse conceito. Barroso (2002) traz duas definições: 1) a cultura tradicional, vista como um conjunto de informações enciclopédicas, tais como, literatura, história, música, arte e 2) a cultura relacionada aos valores, costumes, hábitos, formas de agir, elaboração de conceitos como beleza, tempo, justiça, etc.

De acordo com esse segundo entendimento, cultura tem uma ligação profunda com o modo como um povo se relaciona com o mundo. Godoi $(2005$, p. 1) complementa essa ideia:

\footnotetext{
Sabemos que uma língua é muito mais que léxico, estruturas e uma bonita pronúncia. E o falante de uma língua - como também o aluno que está aprendendo uma língua estrangeira, o aprendiz de falante - é muito mais que um aparelhinho que emite e recebe informações. Uma língua encerra em si mesma a história do seu povo, suas tradições, as características culturais de uma comunidade. Assim, o ensino de uma língua estrangeira tem que passar, necessariamente, pelo conhecimento da cultura. (GODOI, 2005, p. 1)
}

Cordeiro e Werner (2011) chamam atenção para o caso específico do portuguêsespanhol. Como as duas línguas são semelhantes, cria-se a falsa impressão de que a aprendizagem é muito simples e de que alguns problemas de comunicação podem ser resolvidos de maneira intuitiva. Abordando o mesmo tema, Godoi (2005) observa que essa conclusão superficial embasa o grande número de listas de falsos cognatos, heterotônicos e 
heterossemânticos, acreditando-se que, para aprender uma língua estrangeira, basta organizar o léxico estrangeiro da maneira como organizamos o nosso.

Uma vez que admitimos que a cultura faz parte da língua e que aprender uma língua estrangeira passa, impreterivelmente, por compreender os valores que embasam o modo de compreender o mundo de determinado povo, chegamos a um dos temas principais deste trabalho: o lugar da cultura dentro do livro didático. Relacionando o tema com os objetivos propostos no trabalho, levanta-se o seguinte ponto: o lugar da cultura dentro de um livro didático utilizado por aprendizes que estão em situação de imersão. Estudantes nessa posição são capazes de não só entender mais profundamente a cultura do povo em questão, mas também de vivenciar essa nova cultura em seu dia a dia.

\section{METODOLOGIA}

Esta pesquisa tem caráter empírico com uma postura qualitativa com o suporte da fenomenologia. Tal caracterização significa que são levados em conta fatores subjetivos, tais como percepções e compreensão do contexto cultural (TRIVIÑOS, 1987). Além disso, não são levados em conta dados quantitativos, capazes de formar estatísticas, em outras palavras, não importa a quantidade de participantes, mas o que importa são as contribuições que cada participante individualmente pode fornecer, tendo em vista que o foco está no processo vivenciado por cada sujeito, não sobre o conjunto de resultados em si.

Os nove participantes entrevistados constituem um grupo de alunos de origem hispânica, ou seja, todos têm a língua espanhola como língua materna. Eles frequentam aulas de PFOL em uma universidade pública de Curitiba. Seus nomes serão alterados a fim de preservar suas identidades. Quatro desses alunos frequentam as aulas há dois semestres, os outros frequentam há um semestre.

Durante o primeiro semestre de 2015, a professora-pesquisadora, autora deste artigo, ministrou aulas de português a esse grupo de alunos em aulas divididas em dois encontros semanais de 1 hora e 40 minutos cada encontro. Para a realização desta pesquisa, foram selecionadas três atividades didáticas do livro Novo Avenida Brasil 2. Essas atividades estão nas páginas 15,19 e 35 . A primeira delas apresenta um texto sobre a prática de exercícios na praia de Ipanema no Rio de Janeiro, a outra traz um trecho da Constituição Brasileira, cujo conteúdo trata dos direitos trabalhistas brasileiros e a última expõe algumas explicações sobre o comportamento do brasileiro ao receber visitas e ao visitar amigos. 
As três atividades tratam de temas culturais, sob diferentes aspectos. O texto de Ipanema é um texto jornalístico e fala sobre uma das praias mais representativas do Brasil. Lugar onde sempre são gravados programas de televisão, onde acontecem eventos culturais e esportivos. Todos os brasileiros já ouviram falar da praia de Ipanema, assim como já viram imagens dessa praia. Por esse motivo, ela é representativa para o Brasil. A segunda atividade traz um texto da Constituição, portanto, com uma linguagem mais complexa do que o primeiro. Nesse texto, encontram-se explicações referentes aos direitos trabalhistas, encontrados em alguns trechos do Artigo 7 do capítulo 2. A terceira atividade apresenta, através de imagens e pequenos textos, alguns traços típicos do comportamento do brasileiro no que se refere a receber visitas e a visitar. Esse texto conta com uma linguagem mais despojada.

Essas atividades foram realizadas ao longo do semestre. Uma no início das aulas, outra na metade do curso e a última no final. No fim do semestre, cada um dos alunos foi entrevistado individualmente e respondeu uma entrevista que tinha como roteiro inicial as seguintes perguntas ${ }^{1}$ :

1) Há quanto tempo você está no Brasil?

2) Por que você está aqui?

3) Quando você decidiu vir ao Brasil, o que você esperava encontrar? As expectativas foram concretizadas?

4) Descreva o Brasil. O que te chama atenção, o que você gosta, o que você não gosta?

5) As aulas de português te auxiliaram? Em que sentido?

6) Sobre o texto Garotas de Ipanema, qual é a sua opinião? Porque você acha que o autor do livro julgou importante colocar um texto que fale sobre essa região do país? Você já tinha ouvido falar sobre ela?

7) Sobre o texto Os direitos dos trabalhadores, você acha que ele o ajudou? Por que?

8) Sobre o texto Comportamentos, qual é a sua opinião? As informações contidas no texto são verdadeiras?

As quatro primeiras perguntas têm o objetivo de situar o sujeito da pesquisa, verificar seus objetivos no Brasil, bem como suas motivações para estar no país. A quinta pergunta pretende constatar a relevância das aulas de português para ele, verificar sua validade e sua

\footnotetext{
1 As perguntas seguiram esse roteiro, mas não eram fixas. Dependendo das respostas fornecidas, a pesquisadora poderia inserir mais perguntas ou adaptar as que já existiam. O objetivo não era apresentar um formato de questionário com perguntas pré-estabelecidas e imutáveis, mas estabelecer um roteiro com liberdade para alterar ou adaptar os questionamentos, de acordo com as respostas dos participantes.
} 
utilidade, já que eles estão em situação de imersão, ou seja, estão em contato constante com a língua estrangeira. As três últimas perguntas objetivam tratar das atividades didáticas propriamente ditas e verificar se atividades com enfoque cultural são, para eles, válidas, tendo em vista sua situação de estrangeiros vivendo fora de seu país de origem.

As entrevistas foram gravadas e depois transcritas integralmente. Em seguida, foram selecionados trechos das respostas dos alunos para análise e conclusão. As respostas selecionadas foram aquelas nas quais se pode perceber fortemente o reconhecimento da importância (ou não) dos aspectos culturais. Em outras palavras: a autora buscava perceber como as impressões dos alunos sobre as atividades desenvolvidas, cujo enfoque era cultural, pareciam-lhes importantes ou não e por quais motivos.

\section{ANÁLISES DAS ENTREVISTAS}

Excerto 1:

PESQUISADORA: Você acha importante falar sobre cultura durante a aula de português?

ALUNO: Eu acho que é importante pra você não ficar ... chato. Quando uma pessoa convida você para jantar, para sair, ou a pessoa chega tarde, você acha que... que... não está bem e, na verdade, está bem porque são assim. Então acho que... é importante conhecer essas coisas.

Nessa resposta, o aluno afirma que, para ele, falar sobre cultura na aula é importante. Ele diz que não quer ficar "chato", ou seja, para ser aceito nessa nova cultura, é importante conhecer alguns códigos culturais que fazem parte dos costumes. Assim como esse aluno, todos os outros concordaram sobre a importância de se abordar temas culturais na aula de língua estrangeira, tal como no excerto 2 :

\section{Excerto 2:}

PESQUISADORA: Essas três atividades não são de "aprender a escrever", por exemplo, mas são atividades que falam sobre o Brasil. O que você acha disso?

ALUNO: Essa aqui é a realidade, o dia a dia (p. 35). Se me convida uma amiga brasileira, como que eu chego a sua casa?... Eu acho que é bom. 
Essa fala também revela a preocupação do aluno em se inserir socialmente, ou seja, sentir-se parte daquela cultura, ser acolhido por aquelas pessoas. Para conseguir sentir-se dessa forma, eles reconhecem que conhecer os aspectos culturais é fundamental.

\section{Excerto 3:}

PESQUISADORA: Você vem pra aula de português pra aprender a falar português e aí a gente estuda um texto desses que fala dos direitos do trabalhador brasileiro, ele é importante?

ALUNO: Eu sempre achei que é importante, se você está morando fora de seu país, é sempre importante saber algo de cultura, algo de costumes, como pra que a gente de, alguma forma, se... é... se identifique... se misture, es importante.

A vontade de misturar-se revela que conhecer a cultura representa, para esses alunos, muito mais do que um conhecimento acadêmico ou enciclopédico, que se resumiria a conhecer datas/história e pontos turísticos. Trata-se de um desejo de integrar-se a essa nova realidade. A ideia de "mistura" trazida por esse aluno nos deixa clara a necessidade de fazer parte de algo, de entender e de ser entendido, não só linguisticamente.

\section{Excerto 4:}

PESQUISADORA: Porque essa atividade é importante? (p. 35)

ALUNO: Porque nós vivemos numa sociedade, tem muitos tipos de pessoas, será que se eu chego a uma casa que eu sou convidada e faço, não sei, algo inadequado, aí vão ficar "nossa, como que é essa, né" (risos). Não vão gostar.

Esse aluno traz a ideia de "viver em sociedade". Novamente, faz-se referência à necessidade de se sentir integrado a uma comunidade. Nesse sentido, as atividades que tratam de temas culturais os auxiliam. A preocupação por não fazer "algo inadequado" revela o desejo de ser bem visto e de sentir-se bem ao lado das pessoas com quem se convive. Trata-se do desejo de sentir-se aceito dentro do grupo.

\section{Excerto 5:}

PESQUISADORA: Qual é a atividade mais significativa? 
ALUNO: A dos direitos (p. 19). Porque enquanto você conhece um país, as pessoas, você vai aprendendo muitas coisas, então elas... vão ensinando você, mas você não chega conhecer uma pessoa e ela vai falar você tem direito de fazer uma coisa, então acho que é muito importante aprender isso nas aulas.

Nesse caso, o aluno se refere à atividade que aborda os direitos trabalhistas. Muitas vezes, os estrangeiros não sabem como funcionam as leis do país onde vivem. Tampouco há lugares onde eles possam solucionar suas dúvidas em relação a questões específicas. Por isso, mostrou-se muito relevante, para eles, aprender sobre esse tema na aula de português. Esse é um assunto que, além de fazer parte da cultura, suscita uma análise que os ajuda a perceber como é visto o trabalhador dentro da nossa sociedade, assim como, ajuda-lhes a identificar se seus direitos estão sendo cumpridos.

\section{Excerto 6:}

PESQUISADORA: Elas [as atividades] foram úteis pra você? (textos p. 19 e 35)

ALUNO: Muito, porque você como estrangeiro, não conhece todos os direitos que você tem em um país diferente, então, esse daqui (p. 19) ajudou muito se alguém está procurando trabalhar ou... conhece outra pessoa que é estrangeira e está trabalhando e não sabe que tem direitos e... este daqui (p.35) também muito... muito bom porque as costumes são diferentes ainda sendo muito parecidas as culturas você acha que algumas coisas não são legais e são legais aqui.

Essa fala revela que tanto a atividade que tratou dos direitos trabalhistas quanto a que tratou do comportamento foram relevantes de diferentes modos. A atividade dos direitos contribuiu porque elucida os direitos que o trabalhador possui e as reivindicações que pode fazer. A atividade do comportamento os ajudou a perceber que certas atitudes que lhe pareceriam inadequadas ou sinais de desrespeito, eram, na verdade, diferenças culturais. A compreensão desses diferentes modos de comportar-se ajuda a evitar mal-entendidos e choques culturais, já que é um modo de auxiliar o estrangeiro a compreender que se trata somente de uma maneira distinta de entender a situação. 


\section{CONSIDERAÇÕES FINAIS}

Os alunos se mostraram muito receptivos às atividades e concordaram que esse tipo de exercício com enfoque cultural é muito válido já que, segundo alguns deles, aprender a falar uma língua não é simplesmente aprender uma nova gramática, mas também conhecer os costumes e hábitos do povo. Alguns salientaram também que lhes pareceu muito importante discutir essas questões porque, para eles, que vivem em um país estrangeiro, relacionar-se com as pessoas pode representar uma dificuldade a ser superada.

Das três atividades analisadas, as que se mostraram mais atrativas foram a que se refere às leis trabalhistas e a que se refere ao comportamento. A que trata dos exercícios na praia de Ipanema foi vista muito mais como uma curiosidade não representando um conhecimento que lhes pareceu muito relevante.

Assim sendo, pode-se afirmar que, apesar de viver em uma situação de imersão na língua alvo, esses estudantes concordaram que o espaço da sala de aula pode se mostrar como um lugar onde se discute a cultura e os comportamentos das pessoas que vivem no Brasil. Exercício esse que representa, para os estrangeiros, um auxílio em seu processo de aprendizagem.

Um dos pontos verificados e que vale a pena ser abordado é o fato de que, como o universo pesquisado foi pequeno, os resultados não podem ser tomados como generalização absoluta, até porque não era esse o objetivo principal da pesquisa, dado o caráter interpretativista ao qual a investigação se propõe. Assim sendo, percebe-se que essa não representa uma desvantagem, mas somente uma característica inerente a esse tipo de análise. Uma vez que o objetivo seja captar as impressões pessoais dos alunos, é bastante compreensível que nos limitemos a um número pequeno de participantes e que as respostas individuais guiem nossa análise, trazendo uma compreensão do fato que não pode ser adjetivada como limitante, mas como subjetiva e individualizada.

\section{REFERÊNCIAS}

ALMEIDA FILHO, José Carlos P. O ensino de português como língua não-materna: concepções e contextos de ensino. Acervo digital do Museu da Língua Portuguesa. 2005. Disponível em $<$ http://www.museudalinguaportuguesa.org.br/files/mlp/texto_4.pdf $>$ Acesso em 04/07/2015.

BARROSO, Carlos. Cómo integrar el concepto de cultura en los manuales de enseñanza de E/LE. Em: Congreso internacional de asele el español; lengua del mestizaje y la 
interculturalidad,

13.

2002.

Disponível

em

$<$ http://cvc.cervantes.es/ensenanza/biblioteca_ele/asele/pdf/13/13_0174.pdf $>$ Acesso em 30 jan. 2010.

BERGWEILWER, Cristián Gonzaléz. ISHIHARA, Tokiko. IUNES, Samira A. LIMA, Emma Eberlein O. F. ROHRMAN, Lutz. Novo Avenida Brasil 2. Curso básico de português para estrangeiros. Rio de Janeiro: Grupo Editorial Nacional, 2009.

CORDEIRO, Elisa Novaski. WERNER, Maristela P. Abordagem cultural na aula de língua estrangeira. Revista de letras UTFPR, Curitiba, n. 14, pag 1 a 13, 2011.

CUNHA, Maria J. C. O português para falantes de outras línguas: redefinindo tipos e conceitos. Em: ALMEIDA FILHO, José Carlos P. CUNHA, Maria J. C. (orgs.) Projetos iniciais em português para falantes de outras línguas. Brasília: Editora UnB, 2007. Pag. 13 a 31.

DUTRA, Alessandra. Aquisição do português como língua estrangeira: fenômenos de variações no âmbito fonológico. 2008. 127 páginas. Tese de doutorado - Universidade Estadual Paulista Julio de Mesquita Filho, Araraquara, 2008.

FRANÇA, Oldinê R. de; SANTOS, Cynthia A. B. dos. Visão e Abordagem Cultural de professores em sala de aula de LE (inglês) e os PCNs. Revista Horizontes de Lingüística Aplicada, Brasília, ano 7, n. 2, 2008. Disponível em: $<$ http://www.revistahorizontes.unb.br/images/horizontes/07_02_2008/07_07-02-

2008_horizontes_pgla.pdf.> Acesso em 10 jun. 2011.

GODOI, Elena. La cultura en la enseñanza del español y de las literaturas hispánicas. In: Anuario brasileño de estudios hispánicos XI. São Paulo: Thesaurus, 2001.

Pragmática: A cultura no ensino de línguas. Cadernos do Congresso Nacional de

Linguística e Filologia, v. 9, n. 9, 2005. Disponível em: $<$ http://www.filologia.org.br/ixcnlf/9/01.htm> Acesso em 26 jan. 2010.

LARAIA, Roque de Barros. Cultura um conceito antropológico. Rio de Janeiro: J. Zahar, 2006.

SELLAN, Aparecida Regina Borges. Língua e cultura no ensino-aprendizagem do português: visitas guiadas. Em: GIL, B. D. AMADO, R. S. (organizadoras) Reflexões sobre o ensino de português para falantes de outras línguas. São Paulo: Paulistana Editora, 2012. P. 27 a 32.

TRIVIÑOS, Augusto N. S.. Introdução à pesquisa em ciências sociais: a pesquisa qualitativa em educação. São Paulo: Atlas, 1987.

\section{A AUTORA}

Elisa Novaski Cordeiro é doutoranda em Estudos Linguísticos pela Universidade Federal do Paraná. Suas áreas de interesse são: ensino de português para falantes de outras línguas; ensino de língua espanhola e formação inicial de professores de línguas estrangeiras. Atua como professora efetiva no curso de letras da Universidade Tecnológica Federal do Paraná. E-mail: elisa.novaski@yahoo.com.br 